\title{
Enantioselective total synthesis of (-)- $\alpha$-kainic acid
}

\author{
Mario D. Bachi* and Artem Melman \\ Department of Organic Chemistry, The Weizmann Institute of Science, Rehovot 76100, Israel
}

\begin{abstract}
Kainic acid and (-)- $\alpha$-kainic acid (1) were synthesized. (-)- $\alpha-$ Kainic acid was obtained in $12 \%$ overall yield starting from tert-butyl isocyanoacetate. In the first step a chiral non-racemic oxazoline 19 was prepared. Oxazoline 19 was converted in three steps into the thioformimide 22 derived from a highly functionalized $\alpha$-amino carboxylic acid. It was subjected to $n-\mathrm{Bu}_{3} \mathrm{SnH} / \mathrm{AIBN}$ mediated free radical cyclization to enantiomerically pure pyrrolidine 25 which contain all the structural elements of $(-)-\alpha-$ kainic acid, except for the C-2 acetic acid moiety. This appendage was introduced by a new method of temporary sulfur connection. Accordingly, the 4-isopropenyl group was used as an anchor to which $\mathrm{CH}_{2} \mathrm{CO}_{2} \mathrm{Me}$ was temporarily linked $(26 \rightarrow 13 \rightarrow 14 \rightarrow 15)$. It was then intramolecularly connected through a carbon-carbon bond to the pyrrolidine ring $(15 \rightarrow 16)$, and eventually disconnected from its anchor by a sequential reductive double elimination process in which the isopropenyl double bond was restored $(16 \rightarrow 17)$.
\end{abstract}

$\alpha$-Kainic acid $\mathbf{1}$ is the prototype of the kainoids, a group of neuroexcitatory amino acids which activate particular subtypes of glutamic acid receptors. These amino acids are important substrates in physiological and pharmacological studies of the central nervous system (ref. 1). The synthesis of these compounds continues to attract considerable interest (ref. 2). Two features are common to most of the reported syntheses of (-)- $\alpha$-kainic acid: (a) the substituted pyrrolidine system is obtained through the stereocontrolled formation of the 3,4-carbon to carbon bond; (b) the involvement of compounds carrying an acidic C-2 hydrogen atom is delayed to the end of the synthesis (ref. 2). In contrast to these conventions, our synthetic strategy involves the construction of a substituted heterocyclic system through 4,5-carbon to carbon bond formation by a free radical reaction, and the use of a starting material which already possess the carboxylate group designed to occupy position-2 in kainic acid. The acetic acid residue is stereoselectively introduced at position-3 in an advanced stage of the synthesis. The application of this strategy for the total synthesis of racemic $( \pm)$ - $\alpha$-kainic acid (ref. 3,4$)$ and of natural non-racemic (-)- $\alpha-$ kainic acid 1 is described.

Ethanethiol/AIBN mediated free radical cyclization of isocyanide 2 to pyrrolines 3 and $\mathbf{4}$ proceeds in good yield, but its lacking of stereoselectivity significantly limits its applicability in synthesis (ref. 5). In order to render this type of free radical cyclization useful for the synthesis of $\alpha$-kainic acid attention should be given to the following operations: (a) attachment of the acetic acid moiety to the main heterocyclic backbone; (b) reduction of the (ethylthio)pyrroline ring to a pyrrolidine ring; (c) formal oxidation of the isopropyl group to an isopropylene group; (d) stereocontrol of all three chiral centers.
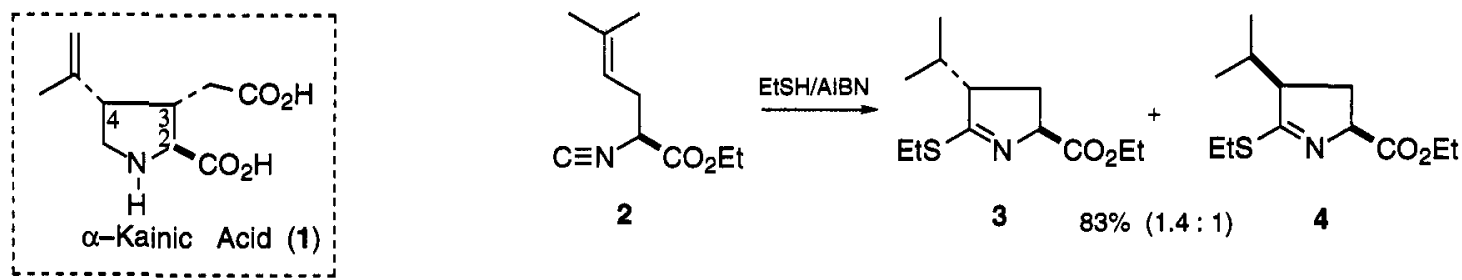

For the efficient of control the stereochemistry at position-4, it seemed reasonable to introduce a steric 
control element at position-3 of isonitrile 5. It was visualized that a group $\mathrm{X}$ in a syn configuration relative to the ester group will direct the ring closure of intermediate radical 6 to give 2,3-cis-3,4-trans substituted pyrroline 7. A stereoisomer 7 could serve our purpose if a method to substitute group $\mathbf{X}$ by an acetic acid residue with inversion of configuration could be found. This problem required particular attention in view of the high susceptibility of such system to $\beta$-elimination. It was however proved (ref. 6 ) that, under suitable conditions, isonitrile $\mathbf{5}\left(\mathrm{R}^{2}=\mathrm{Et}, \mathrm{X}=\mathrm{O}-\mathrm{TBDMS}\right)$ can be synthesized and subsequently subjected to EtSH/AIBN mediated stereoselective cyclization to the tetra-substituted pyrroline $7\left(R^{2}=E t, X=O-T B D M S\right)$.

For the introduction of a 4-isopropenyl group as in $\alpha$-kainic acid (1) instead of the isopropyl group as in 7 we designed, synthesized and cyclized isocyanide 8 . Since in this compound a radical leaving group was placed in a terminal allylic position, treatment with a catalytic amounts of EtSH and AIBN (toluene, 60 ${ }^{\circ} \mathrm{C}$ ), induced a free radical rearrangement to the 4-(isopropenyl)pyrroline 11 (ref 7). The sequential free radical transformation of $\mathbf{8}$ to $\mathbf{1 1}$ involves an intermolecular addition of a thiyl radical to an isonitrile group, an intramolecular addition of a carbon centered imidoyl radical, and $\beta$-elimination of a thiyl radical which continues the chain reaction. The addition-elimination steps $9 \rightarrow 10 \rightarrow 11$ are probably concerted.<smiles>[X]C(C=C(C)C)C(OCC)[N+](=O)OCC</smiles>

5<smiles>[R]C=[N+]([R])C([R])=C([X])C=C(C)C</smiles>

6

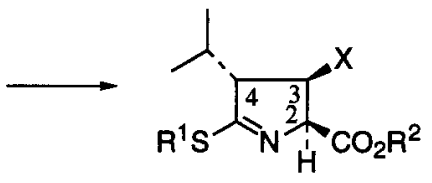

7

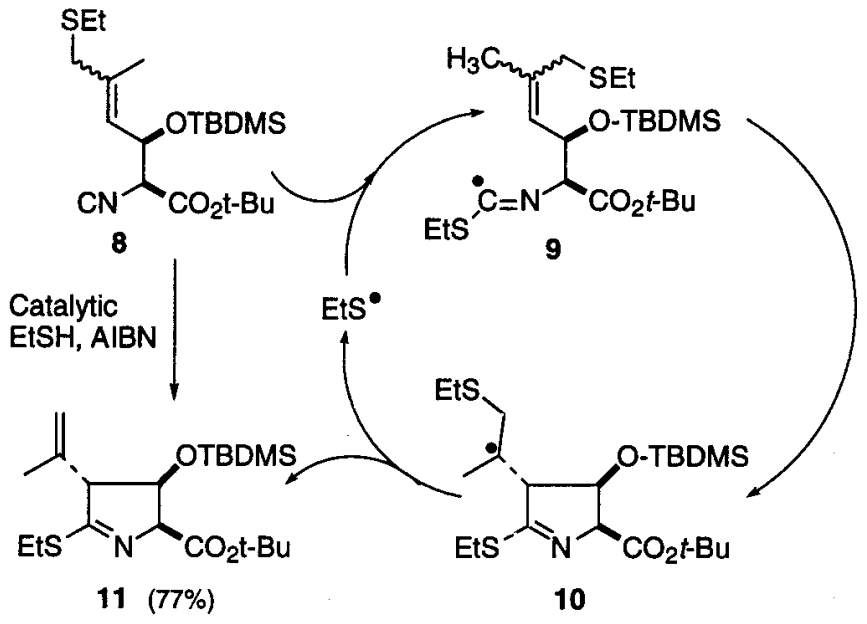

Highly substituted pyrroline 11 was reduced with sodium cyanoborohydride under mild acidic conditions, the resulting pyrrolidine was $\mathrm{N}$-protected with the BOC group to give pyrrolidine 12. Deprotection followed by O-tosylation of the hydroxyl group afforded the desired key compound 13. To complete the synthesis of $( \pm)$ - $\alpha$-kainic acid (1) it was necessary to substitute the tosyloxy group by an acetic acid residue with inversion of configuration. An intermolecular $S_{N} 2$ substitution was excluded due to the competitive facile elimination of $\mathrm{TsOH}$. However, an intramolecular substitution was considered feasible, provided the isopropenyl group which is in the desired $\alpha$-configuration could be used as an anchor for the temporary linking of an acetic acid residue. The substitution of the tosyloxy group by the carbon nucleophile can in principle occur through an intramolecular $\mathrm{S}_{\mathrm{N}} 2$ mechanism, or through elimination of toluenesulfonic acid followed by an intramolecular Michael addition. In order to secure an effective stereocontrol, whatever is the mechanism of this reaction, the acetic acid residue should be linked to the inner end of the isopropenyl group by a one-atom linker. Such an arrangement should lead to the formation of a cis fused five membered ring system. Another requisite for this temporary connection requires the selection of a linker that can be extruded, after the formation of the permanent bond between the acetic acid residue and the pyrrolidine ring, with concomitant regeneration of the double bond in its original site. Since known methods for temporary connection of carbon appendages (ref. 8) could not serve our purpose, we 'were prompted to invent a new type of temporary tethered reactions. We selected sulfur as the temporary linking unit for the following reasons: (a) a variety of reactions allowing the regiocontrolled addition of sulfurcompounds to terminal double bonds are available. (b) several efficient methods for selectively cleaving carbon-sulfur bond are available. (c) both thio- and sulfonyl substituents on acetic esters increase the acidity of the $\alpha$-hydrogen atoms and therefore allow the generation of the nucleophilic center under mild basic conditions.

Addition of $\mathrm{ClCH}_{2} \mathrm{CO}_{2} \mathrm{Me}$ to the double bond of the isopropenyl group of 13 afforded the chloroalkyl sulfide 14 carrying a suitably positioned acetic moiety. Oxidation to the corresponding chloroalkyl sulfone 
15 followed by treatment with MeOK afforded the desired bicyclic system 16. The isopropenyl group was

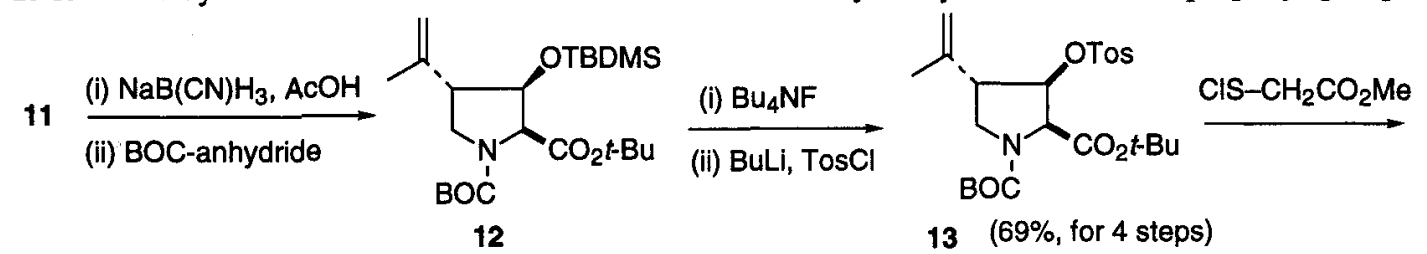

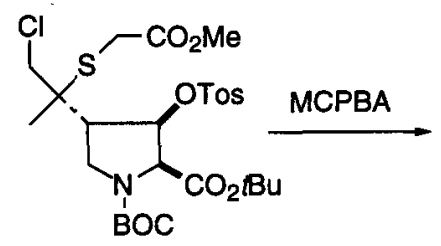

14 (81\%, 1 diastereomer)

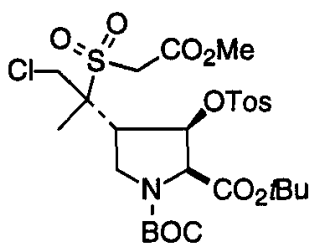

\section{$\mathrm{MeOK} / \mathrm{MeOH} / \mathrm{THF}$}

$15(93 \%)$<smiles>COC(=O)C1C2C(CN1C(=O)OCc1ccccc1)C(C)(CCl)S(=O)(=O)C2COc1ccccc1</smiles>

$16(76 \%)$

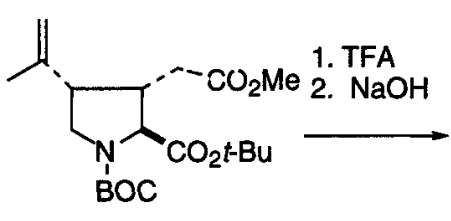

17 (70\%)<smiles>C=C(C)c1c[nH]c(C(=O)O)c1CC(=O)O</smiles>

$\alpha$-Kainic Acid $(1,71 \%)$

eventually restored, and the acetic acid moiety disconnected from its anchor by a new samarium(II) iodidemediated tandem reductive elimination. Thus, chlorine atom extrusion with concomitant ring opening and subsequent sulfur dioxide reductive $\alpha$-elimination afford kainate 17, and after deprotection ( \pm )- $\alpha$-kainic acid (1). ( \pm )- $\alpha$-Kainic acid was thus obtained from the highly functionalized racemic isocyanide 8 in $14 \%$ overall yield.

In principle application of this synthesis to the synthesis of enantiomerically pure (-)- $\alpha$-kainic acid could use the chiral non-racemic isocyanide 8 instead of the racemic isocyanide 8. Considering this option, the Hayashi's reaction (ref. 9) for catalytic addition of isonitriles to aldehydes was used for the addition of aldehyde 18 to tert-butyl isocyanoacetate. Indeed, the major reaction product was found to be the desired enantiomerically pure trans disubstituted oxazoline 19.
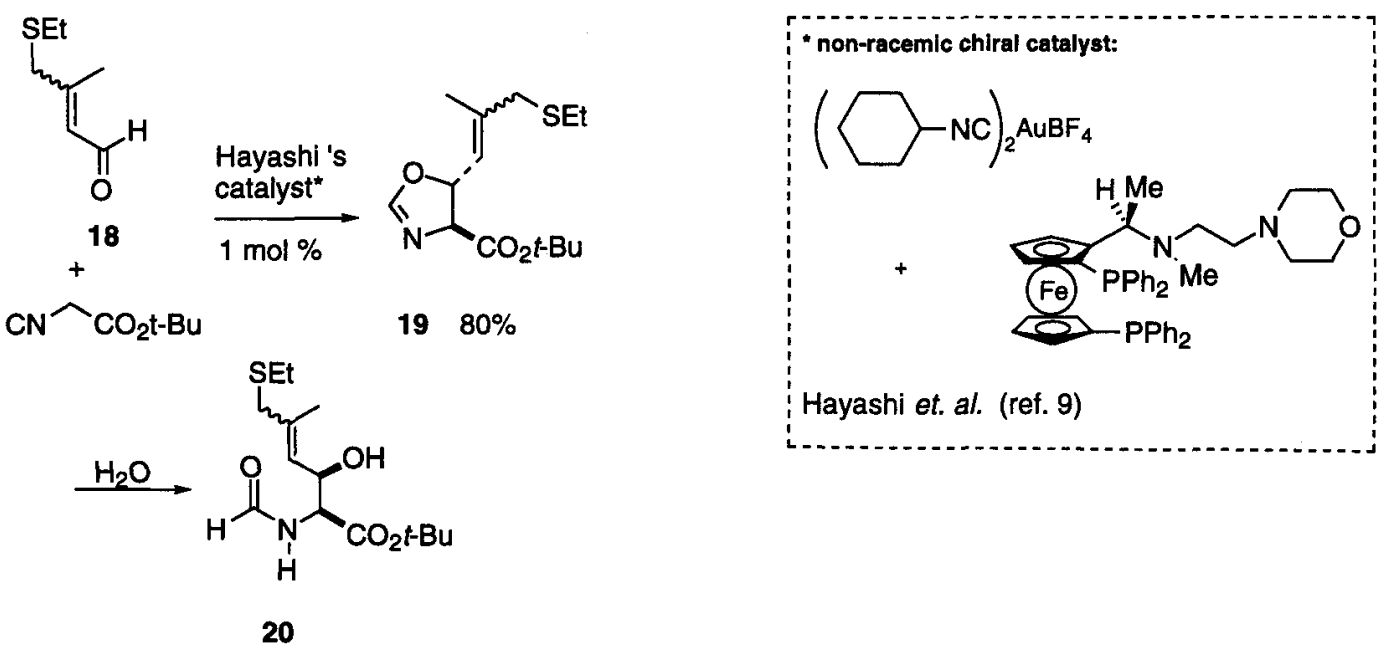

Since hydrolysis to hydroxy- formyl derivative 20, followed by O-protection with TBDMS and dehydration afforded the non-racemic isonitrile $\mathbf{8}$ in unsatisfactory yield, an alternative route using the same oxazoline 19 was developed. Thus, hydrothiolysis of oxazoline 19 gave the thioformamide 21 . Selective 
differential protection of the $\mathrm{NH}$ and $\mathrm{OH}$ groups afforded the thioformimide 22. Treatment of thioformimide 22 with two equivalents of $n-\mathrm{Bu}_{3} \mathrm{SnH}$ and $\mathrm{AIBN}$ in boiling toluene afforded, through the intermediacy of radical 23 and tinthio-derivative 24 the tetra-substituted pyrrolidine 25. Subsequent desilylation afforded the desired enantiomerically pure pyrrolidine derivative $\mathbf{2 6}$ in good yield. It is noted that the electron attracting property of the BOC group in intermediate radical 23 is essential for cyclization as it decreases the degree of stabilization of the cyclizing radical by the adjacent nitrogen atom (ref. 10,11).

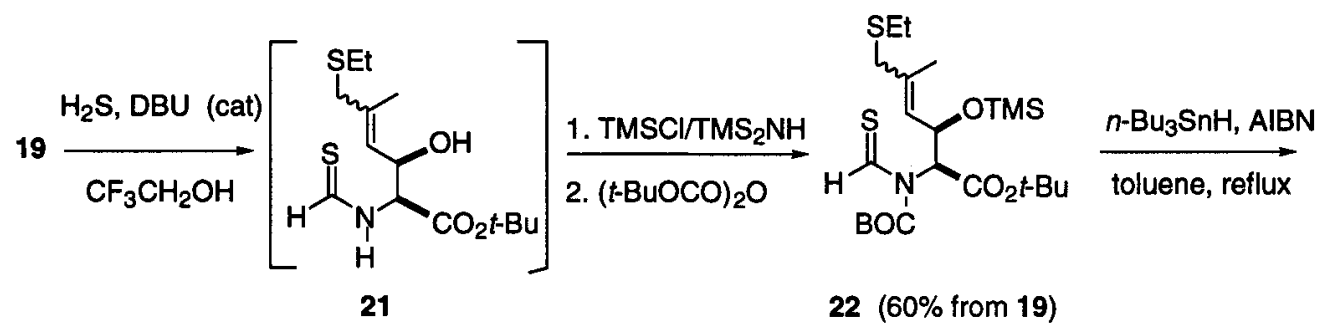

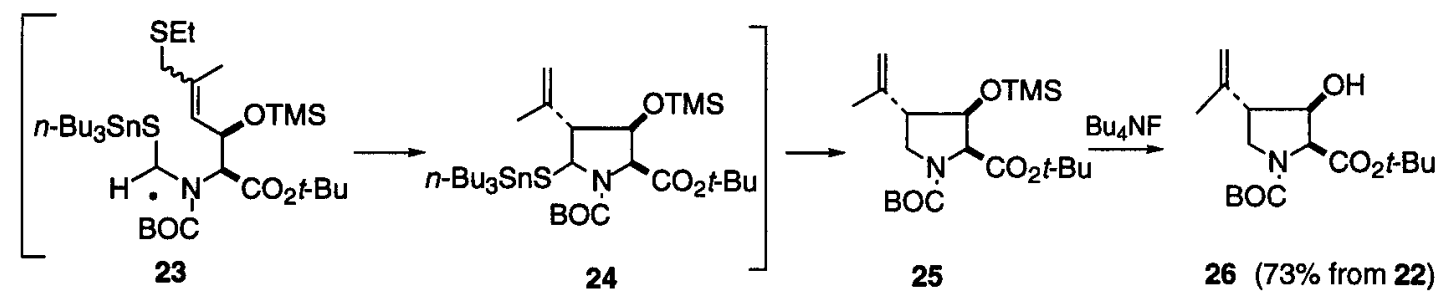

The total synthesis of $(-)-\alpha$-kainic acid was completed using enantiomerically pure pyrrolidine 26 following the same sequence of reactions described above for the conversion of racemic pyrrolidine 13 into $( \pm)$ - $\alpha$-Kainic acid. Enantiomerically pure levorotatory $\alpha$-kainic acid, identical to the natural product, was thus obtained in $12 \%$ overall yield starting from tert-butyl isocyanoacetate.

\section{References}

1. H. Shinozaki, in Exitatory Amino Acid Receptors. Design of Agonists and Antagonists (P.

Krogsgaard-Larsen, J. J. Hansen, Eds.), pp. 261-191. Ellis Horwood, New York (1992).

2. For recent reviews on the synthesis of kainoids see: (a) R. M. Williams, Synthesis of Optically Active $\alpha$-Amino Acids. (E. J. Baldwin, P. D. Magnus, Eds.), pp. 304-320 Pergamon Press, Oxford (1989). (b) A. F. Parsons, Tetrahedron 52, 4149 (1996).

3. M. D. Bachi, A. Melman, Synlett, $60-62$ (1996).

4. M. D. Bachi, N. Bar-Ner, A. Melman, J. Org. Chem. , 61, 0000 (1996).

5. M. D. Bachi, A. Balanov, N. Bar-Ner, J. Org. Chem. 59, 7752-7758 (1994).

6. M. D. Bachi, A. Melman, J. Org. Chem. 60, 6242-6244 (1995).

7. See ref. 5 for a similar isomerization.

8. M. Bols, T. Skrydstrup, Chem. Rev. 95, 1253 - 1277 (1995).

9. Y. Ito, M. Sawamura, T. Hayashi, J. Am. Chem. Soc. 108, 6405-6406 (1986).

10. A. Padwa, H. Nimmesgern, G. S. K. Wong, J. Org. Chem. 50, 5620-5627 (1985).

11. M. D. Bachi, E. Bosch, D. Denenmark, D. Girsh, J. Org. Chem. 57, 6803 - 6810 (1992). 